\title{
Physician Perspectives on Codeine Accessibility, Patterns of Use, Misuse, and Dependence in Saudi Arabia
}

\author{
Mamoon H. Syed ${ }^{1}$. Ayesha Yasmeen ${ }^{1}$ - Marie-Claire Van Hout ${ }^{2}$
}

Accepted: 27 September 2021

(c) The Author(s) 2021

\begin{abstract}
In Saudi Arabia, there are concerning rates of non-compliance with pharmaceutical regulations prohibiting the pharmacy dispensing of prescription-only medications without a physician prescription. This is the first study in the Middle East which examines physicians' perceptions regarding misuse of codeine, listed as a narcotic, controlled, and prescriptiononly drug. The CODEMISUSED survey was adapted to the Saudi Arabian context and pilot tested, prior to cross-sectional administration to physicians in Riyadh, Jeddah, Abha, and Jazan $(n=105)$. Descriptive statistics (frequencies and percentage) present physician level of agreement, neutrality, and disagreement with statements regarding codeine prescribing, patient awareness and use, online and community pharmacy availability, and dependence. The study indicates concern by physicians regarding patient intentional use of codeine to enhance mood, misuse patterns, lack of awareness around habit-forming use and iatrogenic dependence, and sourcing via illegal dispensing. It underscores the imperatives to address pharmacy compliance with pharmaceutical regulatory controls, implement enhanced pharmacovigilance, and improve awareness around safe use.
\end{abstract}

Keywords Codeine $\cdot$ Middle East $\cdot$ Saudi Arabia $\cdot$ Physicians $\cdot$ Pharmacy

\section{Background}

The misuse and abuse of codeine-containing medications both prescribed and over the counter continues to represent a global public health and policy challenge (Bergin et al., 2015; Dada et al., 2015; Myers et al., 2003; Parry et al., 2015; Wells et al., 2018). Despite it being a weak opiate and used to treat mild to moderate pain in adults, misuse is broadly defined as "the use of a medicine, with or without a doctor's prescription, clearly outside of accepted medical practice or guidelines, for recreational purposes or in the framework of self-medication, in greater dosages or for longer periods than were prescribed, in which the risks and problems associated with use outweigh the benefits" (Casati et al., 2012, p.

Marie-Claire Van Hout

m.c.vanhout@ljmu.ac.uk

1 Department of Clinical Pharmacy, College of Pharmacy, Jazan University, Jazan, Saudi Arabia

2 Faculty of Health, Exchange Station, Public Health Institute, Liverpool John Moores University, 3rd FloorTithebarn Street, Liverpool L2 2QP, UK 
230). The maximum recommended dosage of codeine is $240 \mathrm{mg}$ daily (Moore et al., 2001), often in combination with paracetamol, aspirin, or ibuprofen in codeine combination preparations (Foley et al., 2015). A range of related health harms are reported as consequence of prolonged use, high-dose use, and misuse of codeine combination productions, which include acute hemorrhagic necrotizing pancreatitis, hypokalemia, nephrotoxicity, gastrointestinal hemorrhage, dependence, and depression (Barreto et al., 2011; Chetty et al., 2003; Dutch, 2008; Ng et al., 2011; Nielsen et al., 2012; Romach et al., 1999). Substance use disorders are classified as a psychiatric disorder under the DSM-V diagnostic criteria (American Psychiatric Association 2013), with several studies exploring the unique codeine pathways toward iatrogenic dependence, generally commencing with a legitimate medical reason (Parry et al., 2017; Van Hout et al., 2017a, 2017b, 2018).

There is a growing literature base in many countries on consumer access routes and trajectories to codeine misuse and dependence via community pharmacy dispensing and diversion (Carney et al., 2016, 2018; Nielsen et al., 2012; Van Hout et al., 2017b; Wells et al., 2018;). There are increased efforts to develop medical and community practice-based innovations to detect, intervene, and support those affected(Norman et al. 2014; Van Hout, 2014; Van Hout \& Norman, 2016), supported by assessments of medical and pharmacy practitioner perspectives on codeine use, pathways toward misuse and dependence, the detection of patient aberrance, and support interventions (Foley et al., 2016, 2017, 2018).

With most studies on codeine aberrance originating in the UK, Ireland, South Africa, and Australia (Van Hout et al., 2014), very little is known about prescribing patterns, patient use, and misuse of this drug in the Middle East. Research on pain management and patient care (particularly those with non-cancer musculoskeletal pain), prescribing rates of opioids, and consumption trends, are scarce in the Middle East (Cleary et al., 2013; Wilby $\&$ Wilbur, 2017). We report here from the Kingdom of Saudi Arabia (hereafter Saudi Arabia), a high income Islamic country, which has experienced rapid societal change with increased drug consumption patterns (including amphetamine type stimulants, cannabis, heroin, and cocaine) in recent years (Abomughaid et al., 2018; Abualola \& Rahamathulla., 2017; Alhazmi et al., 2020; Kravitz \& Nichols, 2016; Saquib et al., 2020; United Nations Office on Drugs and Crime 2020). Very little is known however regarding pain management, prescribing trends, and patient misuse of opioids (tramadol is most commonly prescribed) in Saudi Arabia (Alharbi et al., 2020; Al-Rowaili et al., 2009; AlRuthia et al., 2020). There are a few pain management clinics in Saudi Arabia, which operate under strict rules for opioid prescription by medical specialists and dispensing regulations by narcotic pharmacists (Alomi, 2017). These strict regulations (in addition to local drug enforcement laws) operate alongside the law that those found engaging in prescription drug diversions can be sentenced to death (Alomi, 2017; Cleary et al., 2013). Of note is that Saudi Arabia was responsible for the most confirmed drug-related executions globally in 2018; at least 59 (Girelli, 2019).

The Ministry of Health $(\mathrm{MoH})$ publishes the Formulary Drug List (MoH 2014) which is publicly available through its website. The Saudi Food and Drug Authority (SFDA) continuously updates and maintains the drugs approved for marketing in Saudi Arabia and also provides the complete list of drugs in a spreadsheet format on its website (SFDA 2021). According to the MOH Formulary Drug List and the Saudi Food and Drug Authority (SFDA), all codeine products are listed as narcotic, controlled, and prescription-only. At the time of data collection, the SFDA website yielded four products currently approved for marketing in Saudi Arabia (see Table 1), all of which were to be dispensed only on a valid prescription from a licensed medical practitioner. The available MoH Formulary Drug List 


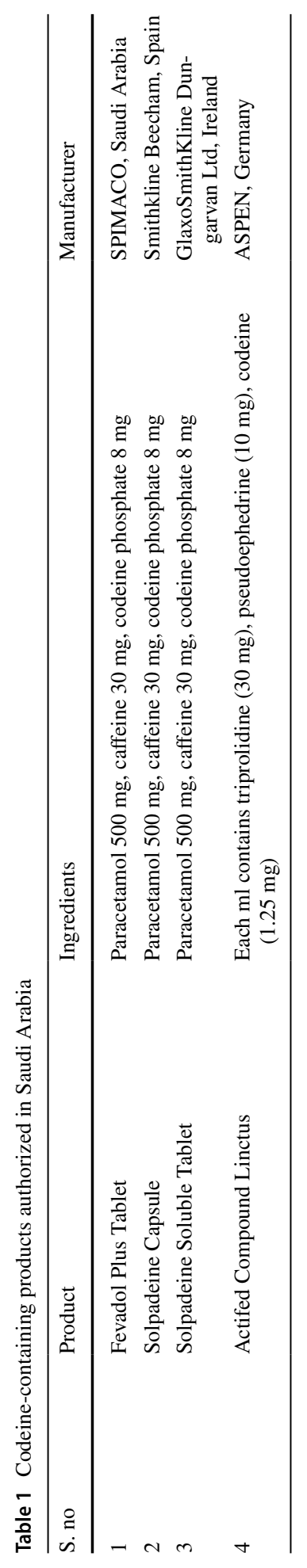


had four codeine items (paracetamol + codeine tablet, paracetamol + codeine + caffeine tablet, codeine phosphate tablet, and codeine phosphate syrup).

The Procedures and Controls for Narcotics and Psychotropic Substances published by the SFDA enlists the regulations pertaining to the acquisition, storage, and dispensing of codeine and the penalties in case of any violation. Despite the regulations, the non-compliance regarding the dispensing of prescription-only medications is a common malpractice in Saudi Arabia, resulting in both inappropriate dispensing and self-medication (Aljadhey et al., 2015; Al-Mohamadi et al., 2013; Sabry et al., 2014). It is common for individuals to access community pharmacies as first port of call prior to a medical practitioner, which has been observed to result in instances of inappropriate dispensing (Hussain et al., 2012; Sabry et al., 2014). Studies have assessed the compliance of community pharmacies with the regulations that prohibit the dispensing of prescription-only medications in the absence of a physician prescription in Saudi Arabia and have reported on concerning rates of noncompliance, including of codeine-containing medicines (Alshammari et al., 2017).

Mobrad et al. (2020) reported in 2020 that the majority of community pharmacists were trained in recognizing the signs of misuse, to provide warnings and counseling to patients. Despite this, there are increased reports of community pharmacy routes to access drugs with potential for misuse (opioids, gabapentinoids) in Saudi Arabia (Alibrahim et al., 2012; AlKhamees et al., 2018; Al-Mohamadi et al., 2013). Corporate chain community pharmacies also operate online pharmacies in Saudi Arabia and have dedicated apps for mobile phone users. These online pharmacies ask the patient to upload their prescription when they select the home delivery option. Possibly, a person sitting at home may upload a codeine prescription to more than one online pharmacy and get it delivered to his/her home from multiple sources. While residents of Saudi Arabia have access to online stores outside the country, these online stores generally restrict supply to only over the counter drugs.

There is a dearth of research in the Middle East and particularly in Saudi Arabia regarding the views and experiences of physician on the misuse of codeine-containing medicines (MENAHRA, 2021). Hence, this is the first study to date which examines their perceptions regarding codeine prescribing, availability, safety, risks, patient use, misuse, and dependence in Saudi Arabia.

\section{Methods}

\section{Research Design}

We adapted the CODEMISUSED survey tool used in previous studies conducted by author three in Ireland, South Africa, and the UK(Foley et al., 2016, 2017, 2018). Once adapted to the Saudi context, the initial draft of the survey questions was then sent to a psychiatrist with specialism in the treatment of addictions for critical review. After incorporation of several suggestions applicable to the Saudi regulatory context, the questionnaire was sent to a three-member expert committee comprising of physicians, two from government hospitals, and an academic physician for face validation so as to ensure the purpose and relevance of the tool was clear to respondents. Consequently, the final version of the study questionnaire contained 20 closed-ended items distributed across four sections. Nine questions pertaining to demographic information were included to indicate the representativeness of the study respondents. All items in the questionnaire requested the respondent to indicate their level of agreement on a 5-point Likert scale. The first section comprised of 
five questions related to codeine prescribing by physicians. The second section included six questions on the availability, safety, and risks of codeine medication available at the community pharmacies. The third section had four questions regarding the physician's perspectives regarding the use pattern of codeine medications by their patients. The fourth section had four questions which probed the opinion of the physicians related to codeine dependence. The online questionnaire was prepared using Google Forms as a survey tool. Lastly, for quality assurance, the online link was piloted with a group of five medical practitioners not partaking in the study.

\section{Recruitment of Participants and Study Procedures}

The study was designed as a cross-sectional study and was conducted in the late 2020. An online and paper-based self-reporting questionnaire tool was employed to elicit responses from a national sample of physicians in Saudi Arabia. Given the sensitivity of the topic, a snowball sampling technique (non-probability sampling) was used. The web link of the questionnaire was initially sent to five physicians, one each from the cities of Riyadh, Jeddah, and Abha and two from Jazan in Saudi Arabia. These five participants were chosen for appropriate representation of age, gender, nationality, qualification, practice setting, and experience. After completion of the survey, respondents were requested to forward the online or paper-based questionnaire to another five colleagues whom they considered suitable for the study. Similarly, the second set of respondents were asked to further direct the link to further respondents and so on. It was ensured that where physicians selected to complete the paper-based survey, that they had not completed the online survey link. The person assigned for data collection through the paper-based format verbally confirmed with the physician if they had filled the questionnaire through the online survey link. Those physicians who had already completed the survey online were excluded from the paper-based survey collection.

\section{Ethical Considerations}

The study was reviewed and approved by the Institutional Research Review and Ethics Committee at Jazan University (REC40/1-008), Saudi Arabia. Participants completed an informed consent form prior to the start of the questionnaire. The participants were briefed about the benefits and risk involved with their participation in the study and were assured of the confidentiality of the data they would provide. The approximate completion time (around $8 \mathrm{~min}$ ) was indicated prior to start of the questionnaire. The respondents were also free to retract from the survey at any point.

\section{Data Analysis}

At the end of the 6-month data collection period, all responses from the Google Forms were downloaded to a Microsoft Excel sheet. The responses obtained through the paperbased questionnaire were manually incorporated into the same data sheet. Prior to analysis, all data were scrutinized for any duplication of responses and/or errors. Thereafter, all data were coded and transferred to the Statistical Package for Social Sciences (SPSS) database (version 23) for statistical analysis (IBM Corporation, Armonk, NY, USA). Descriptive statistics (frequencies and percentage) were employed for data analysis. We present the 
results in terms of level of agreement, disagreement, and neutral responses with each of the statements in tables; and we also present the results grouped as "agree" and "disagree" pertaining to all responses obtained under the level of agreement (for example, "strongly agree" and "agree" were included under the category of "agree"; "strongly disagree" and "disagree" were included under the category of "disagree") in illustrative figures. The neutral responses were retained as such under the third category.

\section{Results}

\section{Participant Profile}

One hundred five physicians completed the survey. About half (48.6\%) of respondents were of the younger age group (25-35 years), and around two-thirds (67.6\%) were male. Nearly two-thirds $(63.8 \%)$ of the respondents were Saudi physicians, and the remaining were expatriates. The demographic characteristics of the study sample are detailed in Table 2.

\section{Codeine Prescribing and Liability for Misuse}

Table 3 illustrates the responses of the physicians pertaining to codeine prescribing. Nearly one-third (30.5\%) were more inclined ("strongly agreed") to prescribe codeine products if the non-opioid analgesics did not work. Only a meager percentage of respondents $(2.9 \%)$ strongly agreed to the statement that patients were cognizant of the adverse effects of taking codeine in higher doses. Likewise, lesser percentage of physicians (2.9\%) strongly agreed that codeine medications carry lesser risk of misuse.

When grouped together, physician experience related to codeine prescribing is depicted in Fig. 1 in terms of total percentage of agreement and disagreement. More than half $(57.1 \%)$ of respondents agreed that they would prescribe codeine combinations to patients when non-opioid analgesics were ineffective. About half $(49.5 \%)$ affirmed an increase in patients' request for codeine-containing medicines. Only about one-third (36.2\%) had difficulty and feelings of awkwardness when asking their patients questions related their codeine use. A similar percentage of respondents (35.2\%) disagreed. Moreover, around three-fourths (78.1\%) showed level of disagreement about the patients' awareness about the adverse effects of high doses of codeine. About two-thirds (68.6\%) disagreed that codeinecontaining medications are less liable to be misused.

\section{Availability, Safety, and Risk Perceptions Regarding Codeine Products}

Table 4 details the responses of physicians to the statements associated with codeine products availability at community pharmacies. Many respondents remained neutral about their concern of availability and easy access through the community pharmacies (39\%), including online pharmacies (40\%); overall, there was a high level of agreement related to their concern. The distribution of responses was nearly similar for "agree," "neutral," and "disagree" in relation to the adequacy of product information on the codeine preparations. Generally, respondents believed that availability of codeine medications at community pharmacy is central to consumer beliefs around safety. Also, respondents mostly disagreed that codeine products at community pharmacy carry lesser risk of misuse. 
Table 2 Demographic details $(N=105)$

\begin{tabular}{|c|c|c|}
\hline & $\mathrm{n}$ & $\%$ \\
\hline \multicolumn{3}{|l|}{ Gender } \\
\hline Male & 71 & 67.6 \\
\hline Female & 34 & 32.4 \\
\hline \multicolumn{3}{|l|}{ Age } \\
\hline $25-35$ years & 51 & 48.6 \\
\hline $35-45$ years & 23 & 21.9 \\
\hline $45-55$ years & 20 & 19.0 \\
\hline More than 55 & 11 & 10.5 \\
\hline \multicolumn{3}{|l|}{ Nationality } \\
\hline Saudi & 67 & 63.81 \\
\hline Non-Saudi & 38 & 36.19 \\
\hline \multicolumn{3}{|l|}{ City } \\
\hline Jazan & 41 & 39.0 \\
\hline Jeddah & 29 & 27.6 \\
\hline Riyadh & 19 & 18.1 \\
\hline Abha & 16 & 15.2 \\
\hline \multicolumn{3}{|l|}{ Qualification } \\
\hline MBBS & 59 & 56.2 \\
\hline MD & 38 & 36.2 \\
\hline $\mathrm{PhD}$ & 8 & 7.6 \\
\hline \multicolumn{3}{|l|}{ Designation } \\
\hline Staff physician & 26 & 24.8 \\
\hline Resident & 46 & 43.8 \\
\hline Consultant & 30 & 28.6 \\
\hline \multicolumn{3}{|l|}{ Practice setting } \\
\hline Government hospital & 58 & 55.2 \\
\hline Public health center (PHC) & 25 & 23.8 \\
\hline Private hospital & 19 & 18.1 \\
\hline Private clinic & 3 & 2.9 \\
\hline \multicolumn{3}{|l|}{ Years of experience } \\
\hline $0-5$ years & 50 & 47.6 \\
\hline $6-10$ years & 21 & 20.0 \\
\hline $11-15$ years & 13 & 12.4 \\
\hline $16-20$ years & 16 & 15.2 \\
\hline 21 years and over & 5 & 4.8 \\
\hline \multicolumn{3}{|l|}{ Location } \\
\hline Urban & 58 & 55.2 \\
\hline Semi-urban & 36 & 34.3 \\
\hline Rural & 11 & 10.5 \\
\hline \multicolumn{3}{|c|}{ Specialist training in substance misuse } \\
\hline Yes & 18 & 17.1 \\
\hline No & 87 & 82.9 \\
\hline
\end{tabular}




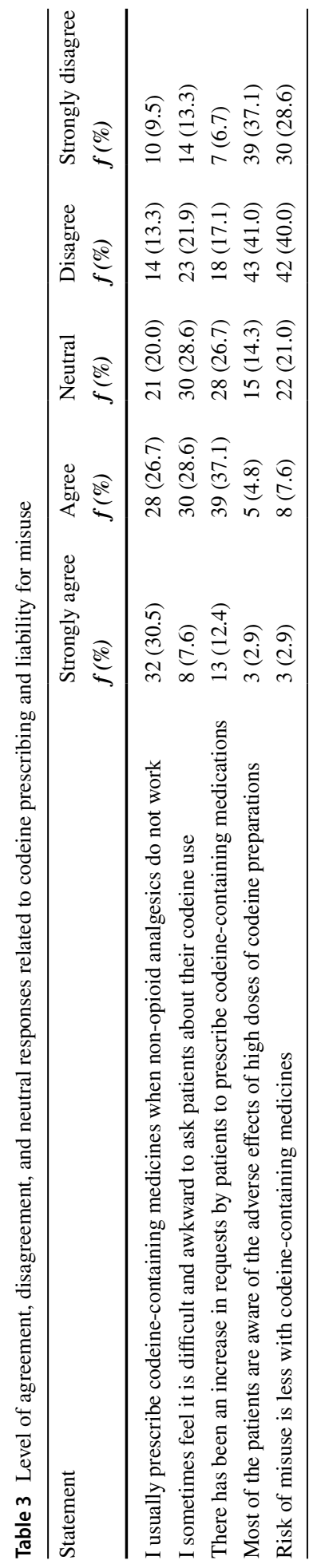




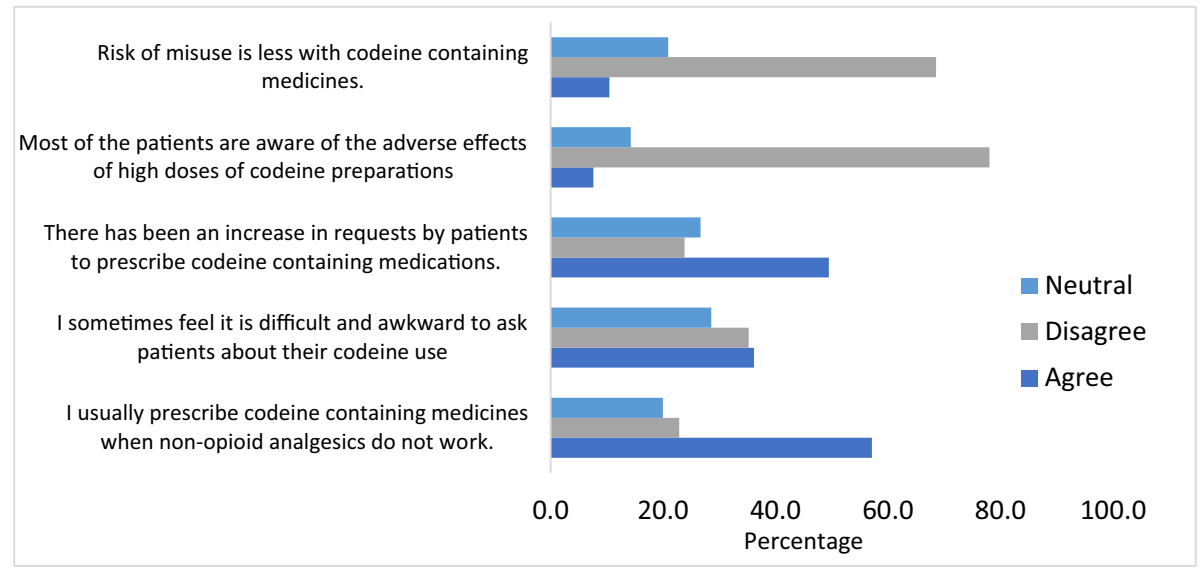

Fig. 1 Level of agreement regarding codeine prescribing and liability for misuse

When grouped together, the perspectives of physicians about the codeine products available at community pharmacies are illustrated in Fig. 2 in terms of total percentage of agreement and disagreement. While codeine-containing medications are not licensed as over the counter products, nearly half $(42.9 \%)$ were concerned about the ease of availability and accessibility of these medications at community pharmacies, while $39 \%$ had no opinion regarding same. $47.6 \%$ were concerned about the codeine products being available through online pharmacies. Fifty-nine percent were of the opinion that patients are unaware about the risk of dependence and agreed that codeine products are safe due to their availability at community pharmacies. Similarly, 59\% disagreed that potential of misuse is less for the codeine products that are available at community pharmacies. For the treatment of mild to moderate pain, only one-third (33.3\%) agreed that codeine products were safe and effective, as opposed to the non-opioid analgesics. Mixed responses were obtained regarding the product information provided to patients who purchase codeine products from community pharmacies.

\section{Patient Use of Codeine}

Table 5 depicts the responses for items indicating the probable reasons for codeine use by patients. There was an overall high level of agreement for all the four listed items in this category.

When grouped together, Fig. 3 illustrates the opinion of physicians regarding patient use of codeine products in terms of total percentage of agreement and disagreement. Sixty-one percent agreed with intentional misuse of codeine-containing products by patients to elevate mood, and a similar percentage (61.9\%) implied that long-term codeine users may deliberately take codeine products to alleviate withdrawal headaches. The majority (75.2\%) agreed that patients are usually unaware of the risks associated with long-term use of codeine medications. Nearly two-thirds $(63.8 \%)$ indicated that patients who take central nervous depressants on prescription are more likely to purchase codeine products. 


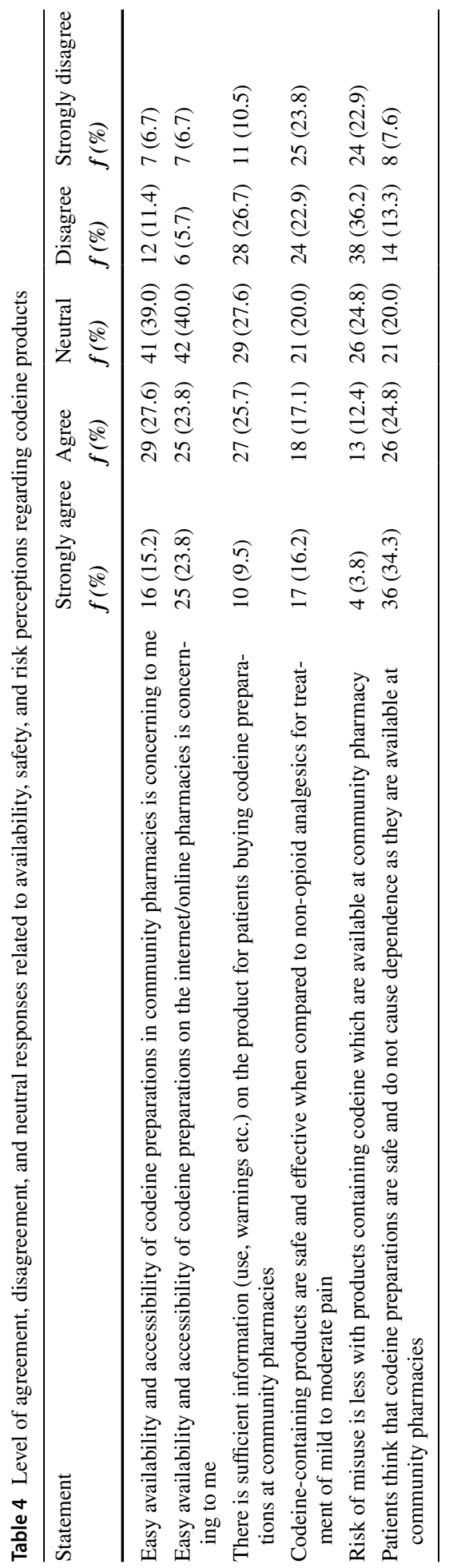




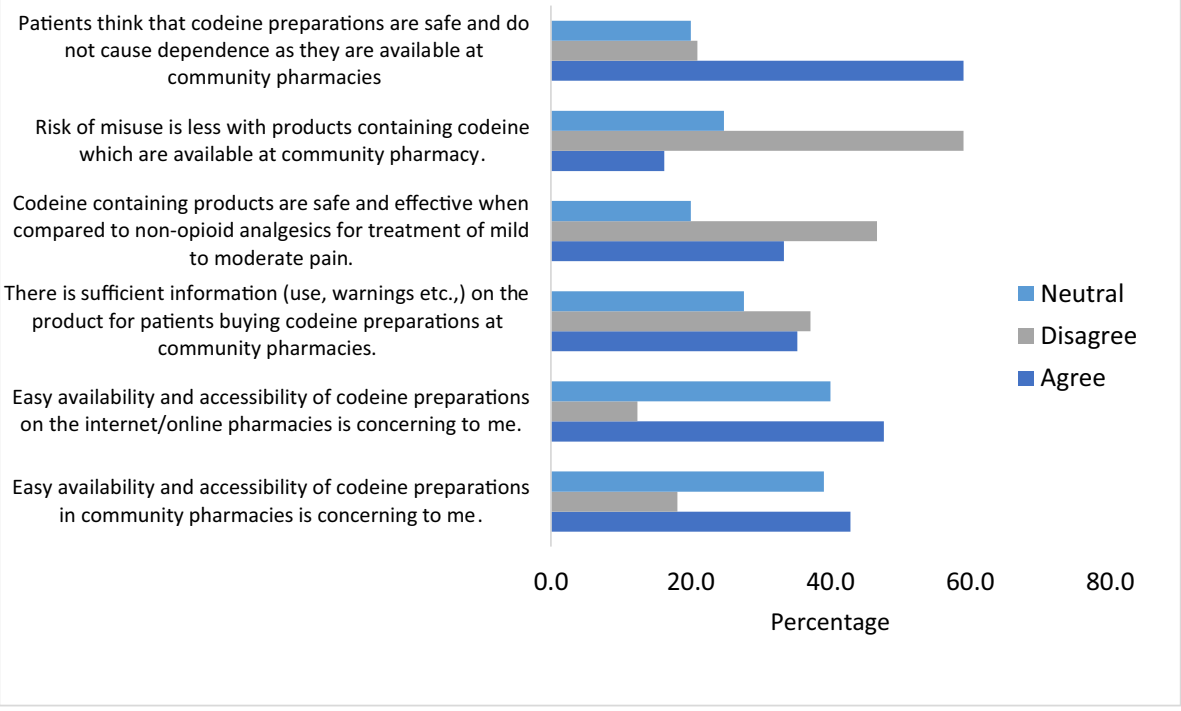

Fig. 2 Level of agreement related to availability, safety, and risk perceptions regarding codeine products

\section{Codeine Dependence}

Table 6 shows physicians' views on codeine dependence. Surprisingly, only one respondent from the study sample strongly agreed to be adept at identifying a patient with codeine dependence. Only a small minority of the participants disagreed (disagree/strongly disagree) that risk of dependence is greater for men as opposed to women. Only four respondents strongly agreed that patients are at a lesser risk of dependence if they take the codeine medication only as prescribed by a medical practitioner.

When grouped together, the physicians' responses about the items examining codeine dependence are shown in Fig. 4 regarding total percentage of agreement and disagreement. Only $25.7 \%$ were confident in identifying codeine dependence in patients. The majority (73.3\%) were of the view that patients taking codeine medications on prescription do not realize that risk of codeine dependence. There was a lack of consensus among respondent with regard to the risk of dependence when a codeine product is used only as prescribed. When asked about higher risk of codeine dependence in males as compared to females, $39 \%$ of respondents agreed, while around half $(54.3 \%)$ remained neutral in their opinion. Half $(50.5 \%)$ agreed that services are available that would screen and support the patients with codeine dependence.

\section{Discussion}

To the authors' knowledge, this is the first study of its kind in the Middle East and presents a unique illustration of physician perspectives on the prescribing of codeine, patient consumption patterns, and levels of awareness of risks and related harms of long-term/high-dose use and dependence in Saudi Arabia. Limitations of the study center on its small-scale cross-sectional nature. It is possible that those physicians with 


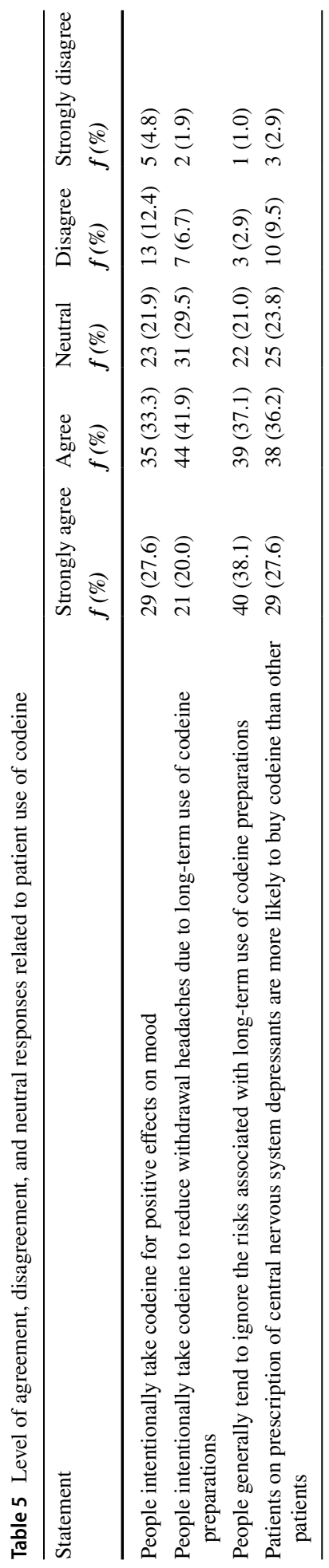




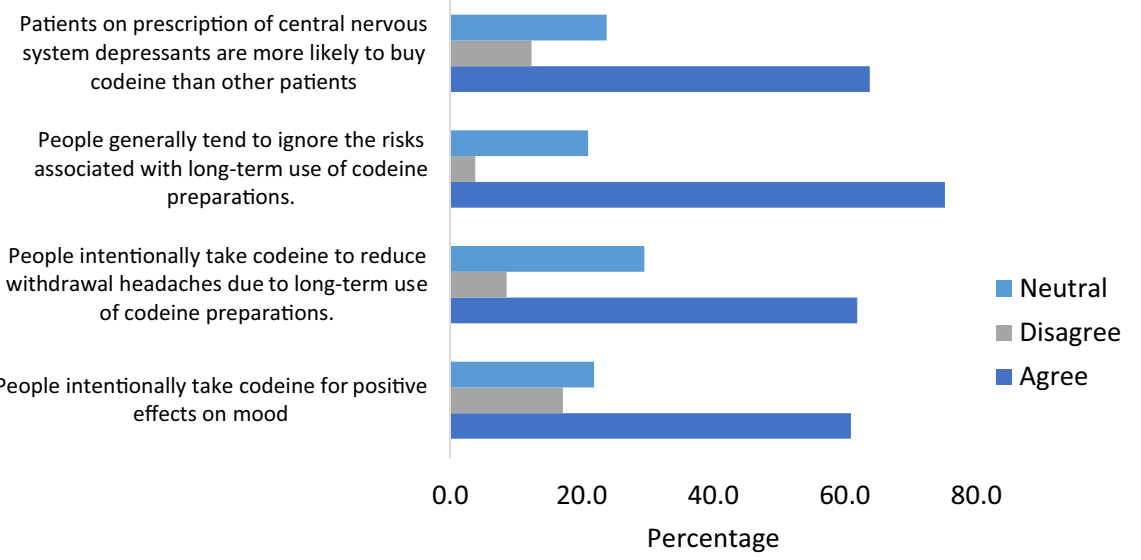

Fig. 3 Level of agreement on patient use of codeine

an interest in addictions or experience of codeine misuse in their practices were more likely to complete the survey. Equally it is likely that misuse and dependence may have different meanings to specific respondents. The study while small-scale is however indicative of medical professional and pharmacy practitioner concerns raised in other parts of the world where codeine is available in community pharmacies (Carney et al., 2016, 2018; Foley et al., 2016, 2017, 2018; Nielsen et al., 2012; Van Hout et al., 2017b; Wells et al., 2018). Countries elsewhere across Europe, Australia, Africa, and the USA have shifted to stronger regulatory controls on over the counter codeine or to only dispense with medical prescription (Tobin et al., 2013). Given that codeine is classed a narcotic, controlled and prescription-only drug in Saudi Arabia, and yet continues to be dispensed illegally via community pharmacy is a grave cause for concern; and indicative of a need for tightening of regulatory mechanisms and pharmacy sanctions to prevent such diversion. Tackling the malpractice of non-compliance regarding the dispensing of prescription-only medications is imperative, especially the case regarding habit-forming medications such as those containing codeine and anti-biotics (Alibrahim et al., 2012; Aljadhey et al., 2015; AlKhamees et al., 2018; Al-Mohamadi et al., 2013; Sabry et al., 2014).

Of note was the strong concern by physicians, largely Saudi nationals, around the routine prescription of codeine to patients with pain, where non-opioid analgesics were ineffective, but with an observable increase in patient requests for codeine-containing medications. There was strong agreement regarding low awareness of patients around risks and harms associated with high dose, long term use and dependence; and as reported elsewhere, concern around the use of codeine for its mood altering properties, and in order to alleviate medication overuse headaches (Katsarava \& Jensen, 2007; Nielsen \& Van Hout, 2015; Van Hout et al., 2017a, 2017b, 2018). As here, studies have highlighted patient lack of understanding around drug terminology, medicines compliance and adherence to recommended regimes, and awareness of side effects (Hurwitz et al., 2014; Salter, 2013). 


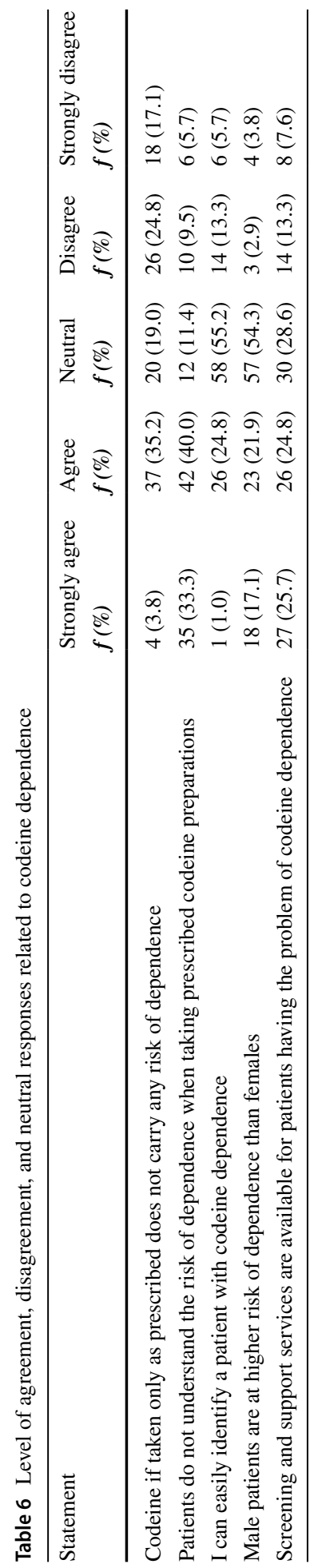




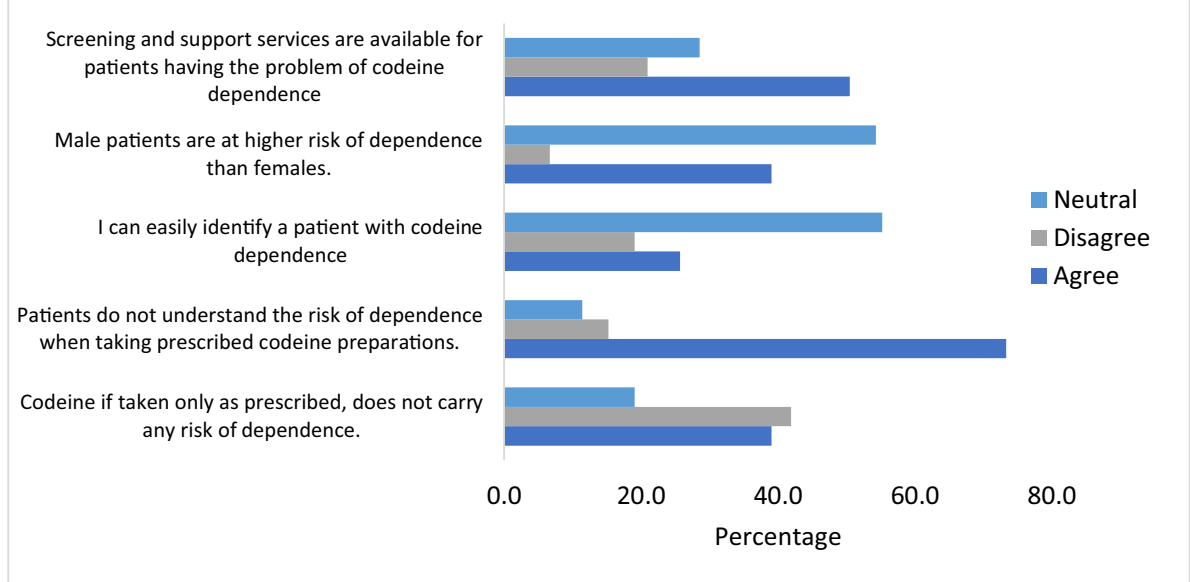

Fig. 4 Level of agreement on codeine dependence

A minority of these physicians reported confidence in identifying codeine dependence in patients. All medical students in Saudi Arabia have to successfully complete 1-year internship training in order to graduate from medical school. Specialized fields such as psychiatry are however usually offered as elective rotations. Therefore, all students may not get the desired training and experience to observe and identify drug misuse and dependence. This is in contrast to a study by Mobrad et al. (2020), which indicated that the majority of community pharmacists are trained in recognizing misuse, providing warnings, and counseling patients. Further adding to the complexity is that findings in our study indicate that patient sourcing of codeine is driven by circumnavigation of online pharmacies and illegal dispensing practices.

Despite both religious and legal prohibitions against possession and consumption of alcohol and narcotics, in response to the rise in substance use among its youth, including problem drug use, the government of Saudi Arabia has ramped up its community substance awareness raising and has shifted its drug policy from zero tolerance toward harm minimisation (Abualola \& Rahamathulla, 2017; Bamofleh et al., 2017; Bassiony, 2013; MENAHRA, 2021; Siddiqui \& Salim, 2016; Sweileh et al., 2014). To date however, Saudi Arabia does not implement harm reduction programs such as opioid agonist treatment, needle and syringe exchange, or naloxone for people who use drugs in the community or in prisons (MENAHRA 2021). We recommend that the Saudi authorities consider to include opiate- and opioid-based pharmaceutical medicines in their prevention, pharmacovigilance, and harm minimization strategies. There is growing national level recognition of the complexities of addressing drug dependence and related comorbidities (Al Harbi, 2017; Ibrahim et al., 2018; Katselou et al., 2016; Saquib et al., 2020). While opioid use is most prevalent in drug treatment patient populations (Alshomrani et al., 2017), we recommend that addiction treatment systems in Saudi Arabia now diversify to recognize and support individuals with codeine dependence and work hand in hand with pain management clinics.

Lastly, the study highlights the need for Saudi authorities to implement and develop medical and community pharmacy practice-based innovations to raise patient awareness, detect aberrance, intervene, and support those affected (Bergin et al., 2015; Norman et al., 
2016; Van Hout \& Norman, 2016; Van Hout, 2014). Further medical education is warranted both at university level, during internships, and during continuing professional development to raise awareness around patient safe use of codeine; the risk factors for misuse and dependence; how best to support pain patients with iatrogenic dependence; and how best to intervene at dispensing point of care. Future research directions could expand to focus on other drugs of misuse available via community pharmacies, for example, the gabapentinoid group.

\section{Conclusion}

This is the first study to date in Saudi Arabia which examines the perceptions of physicians regarding codeine use, misuse, and dependence in Saudi Arabia. It indicates the imperatives of the Saudi government to address Saudi pharmacy compliance with pharmaceutical regulatory controls and implement enhanced pharmacovigilance at prescriber and dispensing levels and a need to improve patient awareness around safe use of codeine-containing medications.

\section{Declarations}

Conflict of Interest The authors declare no competing interests.

Open Access This article is licensed under a Creative Commons Attribution 4.0 International License, which permits use, sharing, adaptation, distribution and reproduction in any medium or format, as long as you give appropriate credit to the original author(s) and the source, provide a link to the Creative Commons licence, and indicate if changes were made. The images or other third party material in this article are included in the article's Creative Commons licence, unless indicated otherwise in a credit line to the material. If material is not included in the article's Creative Commons licence and your intended use is not permitted by statutory regulation or exceeds the permitted use, you will need to obtain permission directly from the copyright holder. To view a copy of this licence, visit http://creativecommons.org/licenses/by/4.0/.

\section{References}

Abomughaid MM, Tayrab EMA, Alghamdi AA. (2018). Prevalence of cannabis and amphetamine in Aseer Region, Saudi Arabia: A retrospective study. Int J Collaborative Research on Internal Medicine \& Public Health, 10(2) Available at Prevalence of cannabis and amphetamine in Aseer Region, Saudi Arabia: a retrospective study I Insight Medical Publishing (imedpub.com)

Abualola, T. H., \& Rahamathulla, M. A. (2017). A review of policies and treatments for addiction to hard drugs: Saudi Arabia, the Netherlands, and Australia. Egyptian J Social Work, 3(1), 43-64.

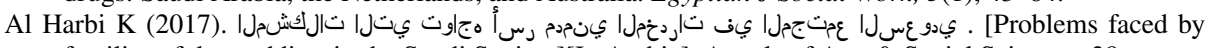
families of drug addicts in the Saudi Society][In Arabic]. Annals of Arts \& Social Sciences, 38.

Alharbi, H. A., Albabtain, M. A., Alobiad, N., Aba Alhasan, J., Alruhaimi, M., Alnefisah, M., Alateeq, S., Alghosoon, H., Alarfaj, S. J., Arafat, A. A., \& Algarni, K. D. (2020). Pain perception assessment using the short-form McGill pain questionnaire after cardiac surgery. Saudi Journal of Anaesthesia, 14(3), 343-348. https://doi.org/10.4103/sja.SJA_34_20

Alhazmi, H. A., Ahsan, W., Al Bratty, M., Javed, S. A., El-Sharkawy, K. A., Khalid, A., Alsalem, H. M., Hakami, A. M., Attafi, M. A., \& Oraiby, M. E. (2020). Analysis of amphetamine and methamphetamine contents in seized tablets from Jazan, Saudi Arabia by liquid chromatography-mass spectroscopy 
(LC-MS/MS) and chemometric techniques. Saudi Pharm J, 28(6), 703-709. https://doi.org/10.1016/j. jsps.2020.04.012

Alibrahim, O., Elawad, N., Misau, Y. A., Shaikh, T. M., \& Allam, N. (2012). Drug dependence and psychotic symptoms: A retrospective study of adolescents who abuse drugs at Al-Amal Hospital in Jeddah Saudi Arabia. J Public Health Afr, 3(1), e5. https://doi.org/10.4081/jphia.2012.e5

Aljadhey, H., Assiri, G. A., Mahmoud, M. A., Al-Aqeel, S., \& Murray, M. (2015). Self-medication in Central Saudi Arabia Community pharmacy consumers' perspectives. Saudi Med J, 36(3), 328-34. https:// doi.org/10.15537/smj.2015.3.10523

AlKhamees, O. A., AlNemer, K. A., Bin Maneea, M. W., AlSugair, F. A., AlEnizi, B. H., \& Alharf, A. A. (2018). Top 10 most used drugs in the Kingdom of Saudi Arabia 2010-2015. Saudi Pharm J, 26(2), 211-216. https://doi.org/10.1016/j.jsps.2017.12.009

Al-Mohamadi, A., Badr, A., Bin Mahfouz, L., Samargandi, D., \& Al, A. A. (2013). Dispensing medications without prescription at Saudi community pharmacy: Extent and perception. Saudi Pharm J, 21(1), 13-18. https://doi.org/10.1016/j.jsps.2011.11.003

Alomi, Y. A. (2017). National pharmacy pain management program at ministry of health in Saudi Arabia. $J$ Pharmacol Clin Res, 3(2), 1-7.

Al-Rowaili, A., Al-aqeel, S. A., Al-Naim, L. S., \& Al-Diab, A. I. (2009). Appropriateness of cancer pain management in Saudi teaching hospital. Gulf J Oncolog, 5, 37-43.

AlRuthia, Y., Alhazzani, H., Alhindi, G., Alarfaj, M., Almutairi, L., Alanazi, M., Alokili, K., Alanazi, N., Alodaibi, F., Alwhaibi, M., Bashatah, A. S., Asiri, Y., \& Alsanawi, H. (2020). Predictors of opioid prescription among a sample of patients with acute musculoskeletal pain at a tertiary care hospital in Saudi Arabia. Journal of Pain Research, 13, 2929-2936. https://doi.org/10.2147/JPR.S276630

Alshammari, T. M., Alhindi, S. A., Alrashdi, A. M., Benmerzouga, I., \& Aljofan, M. (2017). Pharmacy malpractice: The rate and prevalence of dispensing high-risk prescription-only medications at community pharmacies in Saudi Arabia. Saudi Pharm J, 25(5), 709-714. https://doi.org/10.1016/j.jsps.2016.10. 001

Alshomrani, A. T., Khoja, A. T., Alseraihah, S. F., \& Mahmoud, M. A. (2017). Drug use patterns and demographic correlations of residents of Saudi therapeutic communities for addiction. J Taibah Univ Med Sci, 12(4), 304-312. https://doi.org/10.1016/j.jtumed.2017.02.006

American Psychiatric Association (2013). Diagnostic and statistical manual of mental disorders. DSM V-5th edition APA, VA.

Bamofleh, E. A., Mohammed, J. A., Abdelrahim, M. E., \& Gamal, M. (2017). The reasons behind prevalence of Captagon addiction in Jeddah and community awareness: A questionnaire-based study. Pharmaceutical Analytical Chemistry, 2017(1), 20.

Barreto, S. G., Tiong, L., \& Williams, R. (2011). Drug-induced acute pancreatitis in a cohort of 328 patients A Single-Centre Experience from Australia. JOP, 12(6), 581-585.

Bassiony, M. (2013). Substance use disorders in Saudi Arabia: Review article. J Substance Use, 18(6), 450466. https://doi.org/10.3109/14659891.2011.606349

Bergin, M., Norman, I., Foley, M., Harris, R., Rapca, A., Rich, E., \& Van Hout, M. C. (2015). Practice implications and recommendations for managing codeine misuse and dependence. Acta Pharmacologica, 65, 351-364.

Carney, T., Wells, J. S., Bergin, M., Dada, S., Foley, M., McGuinness, P., Rapca, A., Rich, E., \& Van Hout, M. C. (2016). A comparative exploration of pharmacists' views on the nature and management of overthe-counter (OTC) and prescription codeine misuse in three regulatory regimes: Ireland, South Africa and the United Kingdom. Int J Mental Health Addiction, 14(4), 351-369. https://doi.org/10.1007/ s11469-016-9640-z

Carney, T., Wells, J., Parry, C. D. H., McGuinness, P., Harris, R., \& Van Hout, M. C. (2018). A comparative analysis of pharmacists' perspectives on codeine use and misuse - A three country survey. Subst Abuse Treat Prev Policy, 13(1), 12. https://doi.org/10.1186/s13011-018-0149-2

Casati, A., Sedefov, R., \& Pfeiffer-Gerschel, T. (2012). Misuse of medicines in the European Union: A systematic review of the literature. European Addiction Research, 18(5), 228-245. https://doi.org/10. $1159 / 000337028$

Chetty, R., Baoku, Y., Mildner, R., Banerjee, A., Vallance, D., Haddon, A., \& Labib, M. (2003). Severe hypokalaemia and weakness due to Nurofen misuse. Annals of Clinical Biochemistry, 40(Pt 4), 422423. https://doi.org/10.1258/000456303766477101

Cleary J, Silbermann M, Scholten W, et al. (2013). Formulary availability and regulatory barriers to accessibility of opioids for cancer pain in the Middle East: A report from the Global Opioid Policy Initiative (GOPI). Ann Oncol, 2013; 24(11):xi51-xi59. https://doi.org/10.1093/annonc/mdt503 
Dada, S., Harker Burnhams, N., Van Hout, M. C., \& Parry, C. D. (2015). Codeine misuse and dependence in South Africa-Learning from substance abuse treatment admissions. South African Medical Journal, 105(9), 776-779. https://doi.org/10.7196/SAMJnew.8172

Dutch, M. J. (2008). Nurofen Plus misuse: An emerging cause of perforated gastric ulcer. Medical Journal of Australia, 188(1), 56-57. https://doi.org/10.5694/j.1326-5377.2008.tb01509.x

Foley, M., Harris, R., Rich, E., Rapca, A., Bergin, M., Norman, I., \& Van Hout, M. C. (2015). The availability of over-the-counter codeine medicines across the European Union. Public Health, 129(11), 14651470. https://doi.org/10.1016/j.puhe.2015.06.014

Foley, M., Carney, T., Rich, E., Parry, C., Van Hout, M. C., \& Deluca, P. (2016). Medical professionals' perspectives on prescribed and over-the-counter medicines containing codeine: A cross-sectional study. British Medical Journal Open, 6(7), e011725. https://doi.org/10.1136/bmjopen-2016-011725

Foley, M., Carney, T., Harris, R., Fitzpatrick, E., Rapca-Veillet, A., \& Van Hout, M. C. (2017). Medicines containing codeine: Perspectives of medical professionals in the Republic of Ireland. Irish Journal of Medical Science, 186(3), 555-563. https://doi.org/10.1007/s11845-016-1546-z

Foley, M., Carney, T., Rich, E., Dada, S., Mburu, C., \& Parry, C. (2018). A study of medical professionals' perspectives on medicines containing codeine in South Africa. S Afr J Psychiatr, 24, 1162. https://doi.org/10.4102/sajpsychiatry.v24.i0.1162

Girelli, G. (2019). The death penalty for drug offences: Global Overview 2018, Harm Reduction International United Kingdom, 2019. Available at The Death Penalty for Drug Offences I Harm Reduction International (hri.global)

Hurwitz J, Sands S, Davis E, Nielsen J, Warholak T. (2014). Patient knowledge and use of acetaminophen in over-the-counter medications. J Am Pharm Assoc (2003), 54(1):19-26. https://doi.org/ 10.1331/JAPhA.2014.13077

Hussain, A., Ibrahim, M. I., \& Baber, Z. U. (2012). Compliance with legal requirements at community pharmacies: A cross sectional study from Pakistan. The International Journal of Pharmacy Practice, 20(3), 183-190. https://doi.org/10.1111/j.2042-7174.2011.00178.x

Ibrahim, Y., Hussain, S. M., Alnasser, S., Almohandes, H., \& Sarhandi, I. (2018). Patterns and sociodemographic characteristics of substance abuse in Al Qassim, Saudi Arabia: A retrospective study at a psychiatric rehabilitation center. Annals of Saudi Medicine, 38(5), 319-325. https://doi.org/10. 5144/0256-4947.2018.319

Katsarava, Z., \& Jensen, R. (2007). Medication-overuse headache: Where are we now? Current Opinion in Neurology, 20(3), 326-330. https://doi.org/10.1097/WCO.0b013e328136c21c

Katselou, M., Papoutsis, I., Nikolaou, P., Qammaz, S., Spiliopoulou, C., \& Athanaselis, S. (2016). Fenethylline (Captagon) Abuse - Local problems from an old drug become universal. Basic \& Clinical Pharmacology \& Toxicology, 119(2), 133-140. https://doi.org/10.1111/bcpt.12584

Kingdom of Saudi Arabia-Ministry of Health (2014). Formulary drug list. Available at https://www. moh.gov.sa/Ministry/MediaCenter/Publications/Documents/MOH_FormularyDrugList2014.pdf

Kravitz, M., \& Nichols, W. (2016). A bitter pill to swallow: Connections between captagon, Syria, and the Gulf. J Int Affairs, 69(2), 31-44.

Middle East and North Africa Harm Reduction Association (MENAHRA). (2021). Situation on Assessment of Situation and Response of Drug Use and its Harms in the Middle East and North Africa 2020. Retrieved from http://www.menahra.org/images/pdf/Situation_Assessment_2021_-_Web.pdf

Mobrad, A. M., Alghadeer, S., Syed, W., Al-Arifi, M. N., Azher, A., Almetawazi, M. S., \& Babelghaith, S. D. (2020). Knowledge, attitudes, and beliefs regarding drug abuse and misuse among community pharmacists in Saudi Arabia. International Journal of Environmental Research and Public Health, 17(4), 1334. https://doi.org/10.3390/ijerph17041334

Moore, A., Collins, S., Carroll, D., McQuay, H., Edwards, J. (2001). Single dose paracetamol (acetaminophen) with and without codeine for postoperative pain. Cochrane Libr, (2):CD001547. https:// doi.org/10.1002/14651858.CD001547

Myers, B., Siegfried, N., \& Parry, C. D. (2003). Over-the-counter and prescription medicine misuse in Cape Town-Findings from specialist treatment centres. South African Medical Journal, 93(5), $367-370$.

Ng, J. L., Morgan, D. J., Loh, N. K., Gan, S. K., Coleman, P. L., Ong, G. S., \& Prentice, D. (2011). Lifethreatening hypokalaemia associated with ibuprofen-induced renal tubular acidosis. Medical Journal of Australia, 194(6), 313-316. https://doi.org/10.5694/j.1326-5377.2011.tb02982.x

Nielsen, S., Tobin, C., \& Dobbin, M. (2012). OTC codeine: Examining the evidence for and against. Aust Phar, 31(3), 236.

Nielsen, S., Van Hout, M.C. (2015). Over-the-counter codeine-From therapeutic use to dependence, and the grey areas in between. In 'The Misuse of Licit and Illicit Drugs in Psychopharmacology'. 
Bart Ellenbroek, Mark Geyer and Charles Marsden (Eds). Current Topics in Behavioral Neuroscience, Springer Link, 1-17. https://doi.org/10.1007/7854_2015_422

Norman, I. J., Bergin, M., Parry, C. D., \& Van Hout, M. C. (2016). Best practices and innovations for managing codeine misuse and dependence. Journal of Pharmacy \& Pharmaceutical Sciences, 19(3), 367-381. https://doi.org/10.18433/J3T89K

Parry, C. D., Deluca, P., Cooper, R., \& Van Hout, M. C. (2015). Do we have sufficient information to optimally inform regulatory or other policy decisions about medications containing codeine? Addiction, 110(10), 1690-1691. https://doi.org/10.1111/add.13047

Parry, C. D. H., Rich, E., Van Hout, M. C., \& Deluca, P. (2017). Codeine misuse and dependence in South Africa: Perspectives of addiction treatment providers. South African Medical Journal, 107(5), 451-456. https://doi.org/10.7196/SAMJ.2017.v107i5.12242

Romach, M. K., Sproule, B. A., Sellers, E. M., Somer, G., \& Busto, U. E. (1999). Long-term codeine use is associated with depressive symptoms. Journal of Clinical Psychopharmacology, 19(4), 373-376. https://doi.org/10.1097/00004714-199908000-00015

Sabry, N. A., Farid, S. F., \& Dawoud, D. M. (2014). Antibiotic dispensing in Egyptian community pharmacies: An observational study. Research in Social \& Administrative Pharmacy, 10(1), 168-184. https:// doi.org/10.1016/j.sapharm.2013.03.004

Salter, M. D. (2013). Ibuprofen-induced hypokalemia and distal renal tubular acidosis: A patient's perceptions of over-the-counter medications and their adverse effects. Case Rep Crit Care, 2013, 875857. https://doi.org/10.1155/2013/875857

Saquib, N., Rajab, A. M., Saquib, J., \& AlMazrou, A. (2020). Substance use disorders in Saudi Arabia: A scoping review. Subst Abuse Treat Prev Policy, 15(1), 41. https://doi.org/10.1186/s13011-020-00285-3

Saudi Food and Drugs Authority (SFDA)(2021). Available at https://www.sfda.gov.sa/en/drugs-list).

Siddiqui, A. F., \& Salim, A. M. A. (2016). Awareness of substance use and its associated factors in young Saudi students. J Med Allied Sci, 6(2), 61-67.

Sweileh, W. M., Zyoud, S. H., Al-Jabi, S. W., \& Sawalha, A. F. (2014). Substance use disorders in Arab countries: Research activity and bibliometric analysis. Subst Abuse Treat Prev Policy, 9, 33. https://doi. org/10.1186/1747-597X-9-33

Tobin, C. L., Dobbin, M., \& McAvoy, B. (2013). Regulatory responses to over-the-counter codeine analgesic misuse in Australia, New Zealand and the United Kingdom. Australian and New Zealand Journal of Public Health, 37(5), 483-488. https://doi.org/10.1111/1753-6405.12099

United Nations Office on Drugs and Crime (UNODC). (2020). World Drug Report 2020. UNODC, Austria, 2020. Available at World Drug Report 2020 (unodc.org)

Van Hout, M. C. (2014). Doctor shopping and pharmacy hopping: Practice innovations relating to codeine. Drug Alcohol Today, 14(4), 219-234. https://doi.org/10.1108/DAT-03-2014-0014

Van Hout, M. C., \& Norman, I. (2016). Misuse of non-prescription codeine containing products: Recommendations for detection and reduction of risk in community pharmacies. The International Journal on Drug Policy, 2016(27), 17-22. https://doi.org/10.1016/j.drugpo.2015.09.007

Van Hout, M. C., Norman, I., Rich, E., \& Bergin, M. (2017a). Experiences of codeine use, misuse and dependence: Application of Liese and Franz's cognitive developmental model of substance abuse. Behavioural and Cognitive Psychotherapy, 45(3), 238-252. https://doi.org/10.1017/S1352465817000030

Van Hout, M. C., Rich, E., Dada, S., \& Bergin, M. (2017b). "Codeine is my helper": Misuse of and dependence on codeine-containing medicines in South Africa. Qualitative Health Research, 27(3), 341-350. https://doi.org/10.1177/1049732315613764

Van Hout, M. C., Horan, A., Santlal, K., Rich, E., \& Bergin, M. (2018). 'Codeine is my companion': Misuse and dependence on codeine containing medicines in Ireland. Ir J Psychol Med, 35(4), 275-288. https:// doi.org/10.1017/ipm.2015.60

Van Hout, M.C., Bergin, M., Foley, M., Rich, E., Rapca, A.I., Harris, R., Norman, I. (2014). A scoping review of codeine use, misuse and dependence. CODEMISUSED Project. European Commission $7^{\text {th }}$ Framework Programme, EU. Brussels.

Wells, J., Bergin, M., Van Hout, M. C., McGuinness, P., Du Plessis, J., Rich, E., Dada, S., Wells, R., \& Gooney, M. (2018). Purchasing Over The Counter (OTC) Medicinal products containing codeine Easy access, advertising, misuse and perceptions of medicinal risk. Journal of Pharmacy \& Pharmaceutical Sciences, 21(1), 30049. https://doi.org/10.18433/jpps30049

Wilby, K. J., \& Wilbur, K. (2017). Cross-national analysis of estimated narcotic utilization for twelve Arabic speaking countries in the Middle East. Saudi Pharm J, 25(1), 83-87. https://doi.org/10.1016/j.jsps. 2016.01 .001

Publisher's Note Springer Nature remains neutral with regard to jurisdictional claims in published maps and institutional affiliations. 